\title{
The threshold dose for liver tumor promoting effects of dicyclanil in ICR mice
}

\author{
Meilan Jin',2, Yasuaki Dewa', Masaomi Kawai1,3, Jihei Nishimura', Yukie Saegusa',3, \\ Sayaka Kemmochi ${ }^{1,3}$, Tomoaki Harada', Makoto Shibutani ${ }^{1}$ and Kunitoshi Mitsumori ${ }^{1}$ \\ ${ }^{1}$ Laboratory of Veterinary Pathology, Tokyo University of Agriculture and Technology, 3-5-8 \\ Saiwai-cho, Fuchu-shi, Tokyo 183-8509, Japan \\ 2Division of Pathology, Biological Safety Research Center, National Institute of Health Sciences, 1-18-1 \\ Kamiyoga, Setagaya-ku, Tokyo 158-8501, Japan \\ ${ }^{3}$ Pathogenetic Veterinary Science, United Graduate School of Veterinary Sciences, Gifu University, 1-1 \\ Yanagido, Gifu-shi, Gifu 501-1193, Japan
}

(Received September 4, 2009; Accepted November 11, 2009)

\begin{abstract}
To determine the threshold dose of dicyclanil (DC) that induces hepatocellular tumorpromoting effects associated with reactive oxygen species (ROS) generation via their metabolic pathways, partial hepatectomized ICR male mice were fed diets containing $0,187.5,375$ or $750 \mathrm{ppm}$ DC after an intraperitoneal injection of $\mathrm{N}$-diethylnitrosamine (DEN) to initiate hepatocarcinogenesis. Immunohistochemically, the proliferating cell nuclear antigen (PCNA)-positive cell ratio was significantly increased in the DEN + $750 \mathrm{ppm}$ DC group compared with the DEN alone group. However, significant increases in the number of $\gamma$-glutamyltranspeptidase (GGT)-positive cells and formation of microsomal ROS were not observed in the DEN + DC groups compared with the DEN alone group. Real-time polymerase chain reaction (RT-PCR) showed that the expression of Cypla1, Cypla2, and OGGlgenes was significantly upregulated in mice given diets containing $375 \mathrm{ppm}$ DC or more, $187.5 \mathrm{ppm}$ DC or more, and $750 \mathrm{ppm} \mathrm{DC}$, respectively. These results suggest that the threshold dose of DC that induces ROS-mediated liver tumor promotion in mice is more than $750 \mathrm{ppm}$, although expression of the Cypla2 gene, which is related to ROS generation, was up-regulated in the liver of mice, even at a DC dose of $187.5 \mathrm{ppm}$.
\end{abstract}

Key words: Dicyclanil, ROS generation, Threshold dose

\section{INTRODUCTION}

It has been shown that oxidative stress is an important factor that affects the pathogenesis of degenerative and inflammatory diseases, aging, and cancer (Wiseman and Halliwell, 1996; Trush and Kensler, 1991). Indeed, reactive oxygen species (ROS) are believed to play a pivotal role in the etiology of liver cancer, and ROS overproduction and subsequent oxidative DNA damage enhance the development of hepatocellular carcinomas caused by carcinogenic agents, such as the hepatitis $\mathrm{C}$ virus (Moriya et al., 2001), metal (Asare et al., 2006), insecticides (Lin et al., 2007; Schilezinger et al., 1999), and synthetic derivatives of naturally occurring flavonoids (Dewa et al., 2008). In addition, it has been reported that upregulation of c-Myc resulting from the excessive ROS production may play an important role on cellular proliferation in the liver tumor promotion (Kawai et al., 2009).

Dicyclanil (DC), 4,6-diamino-2-cyclopropylaminopyrimidine-5-carbonitrile, is a pyrimidine-derived insect growth regulator that inhibits the molting and development of insects and is used in veterinary medicine to prevent myiasis (fly strike) in sheep. It has been reported that the incidence of hepatocellular carcinomas was increased in mice fed a diet containing $1,500 \mathrm{ppm}$ of DC for 18 months, but negative results were obtained in in vitro and in vivo genotoxicity studies of DC (WHO, 2000). Based on these results, this chemical substance is classified as a nongenotoxic rodent carcinogen (WHO, 2000). In our previous study, to clarify the possible mechanism of DCinduced liver tumor promoting effects, we performed short- and long-term two-stage hepatocarcinogenesis

Correspondence: Kunitoshi Mitsumori (E-mail: mitsumor@cc.tuat.ac.jp) 
studies in which mice were given $1,500 \mathrm{ppm}$ DC after initiating hepatocarcinogenesis with $\mathrm{N}$-dimethylnitrosamine (DMN) (Moto et al., 2005, 2006b). The results of these two-stage hepatocarcinogenesis studies showed up-regulation of cytochrome P450 1A1 and cytochrome P450 1A2 (Cypla1 and Cypla2) and thioredoxin reductase 1 (Txnrd1), which are metabolism- and/or oxidative stressrelated genes, 8-oxoguanine DNA glycosylase (OGG1) and excision repair cross-complementing rodent repair deficiency group 5 (Ercc5), which are DNA damage-/ repair-related genes (Moto et al., 2005). Moreover, there were significant increases in the number of altered foci that were positive for $\gamma$-glutamyltranspeptidase (GGTpositive foci) and in the liver DNA levels of 8-hydroxydeoxyguanosine (8-OHdG), a representative marker of oxidative DNA damage, in mice of the DMN + DC group. In addition, a dose-dependent increase in microsomal ROS production was observed in these mice (Moto et al., 2005, 2006b). These results suggest that DC has the potential to generate ROS via metabolic pathways and induce oxidative stress, including oxidative DNA damage, resulting in the induction of hepatocellular tumors in mice. However, the threshold dose of the liver tumor-promoting effect of DC in mice has not yet been elucidated. Additionally, in our previous study, real-time RT-PCR analysis revealed increased expression of the Cyplal gene and of phase II enzyme genes such as Txnrdl and OGG1 in mice administered DC after an intraperitoneal injection of DMN compared with the gene expression in the corresponding control group (Moto et al., 2006b). Cyplal generates ROS as byproducts of microsomal oxidation, and phase II enzymes are involved in the protection against oxidative stress (Guengerich and Shimada, 1991; Puntarulo and Cederbaum, 1998). Thus ROS generation and protection against ROS by phase II enzymes probably occur concomitantly in mice administered DC after an intraperitoneal injection of DMN. Accordingly, it is considered that the dose increasing ROS generation, cell proliferative activity, GGT positive foci or cell and drug-metabolizing enzymes that protect against ROS is the threshold dose of liver tumor promotion in mice. However, the threshold dose of DC in mice is not known.

In our previous studies, the incidence of hepatocellular tumors (adenomas and carcinomas) significantly increased in partially hepatectomized male ICR mice that were intraperitoneally injected with N-diethylnitrosamine (DEN) and given a diet containing 1,500 ppm of DC for 20 weeks, and gene expression analysis on the micro-dissected liver tissues of the mice in this group showed the highest expression levels of oxidative stressrelated genes, such as Cyplal and Txnrd1, in the hepa- tocellular tumor areas (Moto et al., 2006a). Therefore, in the present study, we selected DEN rather than DMN as an initiator, since it was confirmed that mice were more susceptible to DEN than DMN in our preliminary studies (personal observations). In addition, we used a twostage hepatocarcinogenesis model in mice to identify the threshold dose of DC that induces liver tumor-promoting effects, microsomal ROS generation and drug-metabolizing enzymes that protect against ROS.

\section{MATERIALS AND METHODS}

\section{Animals and chemicals}

Four-week-old male ICR mice were purchased from Japan SLC, Inc. (Shizuoka, Japan) and were maintained on a powdered basal diet (MF; Oriental Yeast, Co., Ltd., Tokyo, Japan) and tap water until they were 5 weeks old. The mice were housed in polycarbonate cages with paper bedding and were maintained under standard conditions (room temperature, $22 \pm 2{ }^{\circ} \mathrm{C}$; relative humidity, $55 \pm 5 \%$; light/dark cycle, $12 \mathrm{hr}$ ). Animal care and experiments were carried out in accordance with the Guide for Animal Experimentation of the Tokyo University of Agriculture and Technology.

DC (CAS No. 112636-83-6) was kindly provided by Novartis Animal Health Inc. (Basel, Switzerland) for the experiment. DEN was purchased from Nacalai Tesque, Inc. (Kyoto, Japan).

\section{Experimental design}

The two-stage liver carcinogenesis model of mice was used based on a modified protocol of Della Porta et al. (1987) and Lee et al. (1989) (Fig. 1). To initiate hepatocarcinogenesis, an intraperitoneal injection of DEN at a dose of $30 \mathrm{mg} / \mathrm{kg}$ body weight was administered to the animals (day 0). Twenty-four hours before the DEN injection, a two-thirds partial hepatectomy was performed on the mice to enhance the regeneration of the liver with DNA damage. One week after the DEN injection, mice were fed a powdered diet containing DC at a concentration of 0 (DEN alone), 187.5, 375 or $750 \mathrm{ppm}$ for 10 weeks. For liver sampling, the survivors at 11 weeks were sacrificed by exsanguination from the abdominal aorta under ether anesthesia.

At necropsy, tissue samples were collected from the remaining lobes of the liver. One-third of these samples were fixed with natural-buffered formalin for histopathological examinations, and one-third was embedded in OCT compound (Tissue-Tek; Miles Inc., Elkhart, IN, USA) and frozen for GGT staining. The remaining liver samples were weighed, frozen in dry ice and stored at $-80^{\circ} \mathrm{C}$ until 
Threshold of tumor promotion in DC

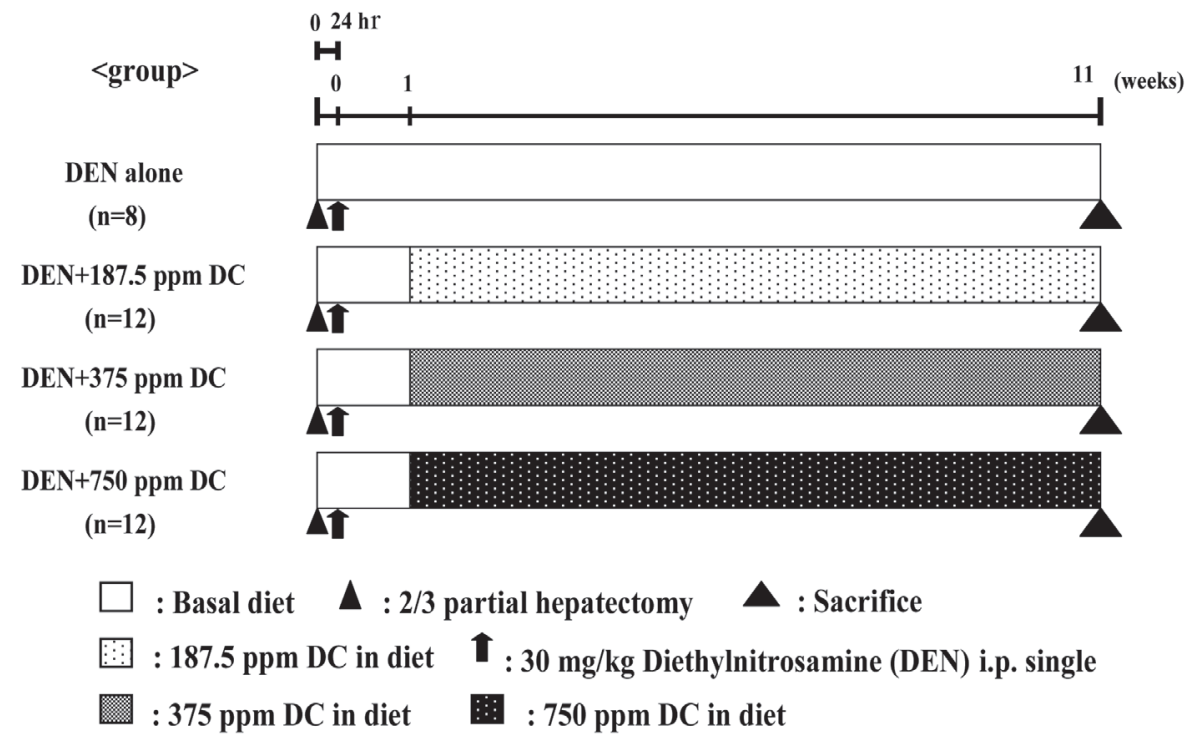

Fig. 1. Experimental design

further analysis.

\section{Histopathological, histochemical and immunohistochemistry evaluations}

Formalin-fixed liver tissues were embedded in paraffin, sectioned, and stained with hematoxylin and eosin (HE) for the histological examinations. Immunohistochemical staining of proliferating cell nuclear antigen (PCNA) antibody (PC10; DakoCytomation, Glostrup, Denmark) was performed by the avidin-biotin-peroxidase complex method. Histochemical staining of GGT was performed by modifying the methods proposed by Rutenberg et al. (1969). The frozen tissues were cryosectioned and fixed using acetone. After air-drying, the freshly prepared solution containing the substrate L-glutamic acid- $\gamma$-(4-metoxy- $\beta$-naphthylamide) (Sigma-Aldrich, St. Louis, MO, USA) and fast blue BBN (Wako Pure Chemical Industries, Osaka, Japan) in $0.1 \mathrm{M}$ Tris-buffered saline ( $\mathrm{pH} 7.4$ ) was coated onto the section. After incubation, the slides were transferred to 0.1 $M$ cupric sulfate solution. The sections were then stained with hematoxylin, and mounted in $10 \%$ glycerol. The number of PCNA-positive cells per 400-500 cells in each slide was counted from ten different areas to determine the PCNA positive index (PCNA PI). The number of GGTpositive cells per area was calculated from the number of positive cells in all lobes on the slide and from the total area in all lobes measured using computer-assisted image analyzer (NIH image).

\section{RNA isolation and real-time RT-PCR}

Total RNA was isolated from the liver samples using TRIzol reagent (Invitrogen Corp., Carlsbad, CA, USA). Reverse transcription (RT) was carried out using ThermoScript RT-PCR System (Invitrogen Corp.), and the cDNA aliquots were used in quantitative real-time RT-PCR with SYBR Green using an ABI Prism 7000 Sequence Detection System (Applied Biosystems, Foster City, CA, USA). The PCR reaction was repeated twice in triplicate for each gene. The PCR primers for the genes of cytochrome P450 1A1 (Cypla1, accession number NM_009992), cytochrome P450 1A2 (Cypla2, accession number NM 009993), 8-oxoguanine DNA-glycosylase 1 (OGG $\overline{1}$, accession number NM_010957), thioredoxin reductase 1 (Txnrd1, accession number NM 015762), aldehyde dehydrogenase family 1 subfamily A1 (Aldhlal, accession number NM_013467), NADPH P450 reductase (Por or NADPH, accession number NM_008898), Excision repair cross-complementing rodent repair deficiency complementation group 5 (Ercc5, accession number NM_011729), superoxide dismutase 1 (Sod1, accession number NM_128337) and Glutathione peroxidase 2 (Gpx2, accession number MN_030677) in the present study were prepared as previously reported (Moto et al., 2005, 2006a and 2006b). The primers used in this PCR are summarized in Table 1. The expression levels of each gene were corrected based on the expression of $\beta$-actin in the same cDNA sample. 
Table 1. Primers of genes used for real-time RT-PCR

\begin{tabular}{|c|c|c|}
\hline Accession number & Abbreviation of gene name & Primer (upper: forward primer, lower: reverse primer) \\
\hline \multirow[t]{2}{*}{ NM_009992 } & Cyplal & AGGATGTGTCTGGTTACTTG \\
\hline & & AGAAACATGGACATGCAAG \\
\hline \multirow[t]{2}{*}{ NM_009993 } & Cypla2 & GCTACTTGTGACATGGCCTA \\
\hline & & AAGCCATTCAGTGAGGTGTC \\
\hline \multirow[t]{2}{*}{ NM_010957 } & Oggl & CAGCATAAGGTCCCCACAGATT \\
\hline & & GCCAACAAAGAACTGGGAAACT \\
\hline \multirow[t]{2}{*}{ NM_015762 } & Txnrdl & GGTTGCATACCTAAGAAGCTGATG \\
\hline & & CCATAGTTGCGCGAGTCTTTC \\
\hline \multirow[t]{2}{*}{ NM_013467 } & Aldhlal & GACTTGAAGATTCAACATACC \\
\hline & & TCACAGCTTTGTCAACATCA \\
\hline \multirow[t]{2}{*}{ NM_008898 } & Por or $N A D P H$ & GCCTGCCTGAGATCGACAAG \\
\hline & & GGGTCGCCTTCTCCGTATGT \\
\hline \multirow[t]{2}{*}{ NM_011729 } & Ercc5 & TCAACTAGGACTGGACCGTAACAA \\
\hline & & AGTTGGTATCCCTTCCGTATAGTCA \\
\hline \multirow[t]{2}{*}{ NM_128337 } & Sod1 & TGATTGGGATTGCGCAGTAA \\
\hline & & TGGTTTGAGGGTAGCAGATGAGT \\
\hline \multirow[t]{2}{*}{ NM_030677 } & Gpx2 & GCTGCCCTACCCTTATGATGAC \\
\hline & & CGCACGGGACTCCATATGAT \\
\hline
\end{tabular}

\section{Measurement of microsomal ROS production in the liver}

Liver microsomes were obtained from four mice from each group treated with $0,187.5,375$ or 750 ppm DC for 10 weeks and which were subjected to the two-stage hepatocarcinogenesis model. Their liver microsomes were extracted using the following method. The liver samples were rinsed with ice-cold homogenate buffer $(1.15 \%$ $\mathrm{KCl}, 0.2 \mathrm{mM}$ ethylene diamine tetra-acetic acid disodium (EDTA-2Na), 0.1 mM dithiothreitol (DTT), $0.1 \mathrm{mM}$ phenylmethylsulfonyl fluoride (PMSF), and 20\% glycerin at $\mathrm{pH}$ 7.4) and homogenized in three volumes of the homogenate buffer using a glass pestle. The homogenate was centrifuged at $10,000 \times \mathrm{g}$ for $10 \mathrm{~min}$, and the supernatant was ultracentrifuged at $105,000 \times \mathrm{g}$ for $90 \mathrm{~min}$. The microsomal pellet was resuspended in the homogenate buffer, and the protein content of the homogenate was determined using the BCA Protein Assay Kit (Pierce Biotechnology, Pierce, IL, USA) with BSA as a standard. For the measurement of ROS, the nonfluorescent probe DCFH-DA was used as to detect ROS formation during cellular metabolism; in the presence of ROS, this probe oxidizes to a highly fluorescent dichlorofluorescein (DCF) (LeBel et al., 1990; Serron et al., 2000; Szejda et al., 1984). The microsomes (0.05 mg protein) were incubated in the dark at $37^{\circ} \mathrm{C}$ in $40 \mathrm{mM}$ Tris buffer ( $\mathrm{pH} 7.4)$ and DCFH-DA $(5 \mu \mathrm{M})$ for $30 \mathrm{~min}$. At the end of the incubation period, $2.5 \mathrm{mM} \beta$-NADPH was added and the sample was incubated at $37^{\circ} \mathrm{C}$ for $30 \mathrm{~min}$ in the dark. ROS formation was detected by measuring the fluorescent product by a microplate reader (excitation, $485 \mathrm{~nm}$ and emission, $528 \mathrm{~nm}$ ).

\section{Statistical evaluation}

Statistical analyses were performed using the statistical software StatLight (Yukms Co., Ltd., Tokyo, Japan), and all results are presented as means \pm S.D. The significance of the differences between the DEN alone group and each DC group was determined by Dunnett's test after one-way ANOVA. A p-value less than 0.05 was considered statistically significant in both analyses. 
Threshold of tumor promotion in DC

\section{RESULTS}

\section{General observations and histological evaluation}

During the experimental period, death and remarkable treatment-related clinical signs were not observed in the DEN alone or the DEN + DC groups. No significant differences in the final body weight, and absolute and relative liver weights of mice were observed in any of the treated groups (Table 2, Fig. 2).

No remarkable histopathological changes were observed in the liver of mice treated with $187.5,375$ or $750 \mathrm{ppm}$ DC. In immunohistochemical examinations, GGT-positive cells were observed in the liver of mice treated with DEN alone or DEN + DC, but GGT-positive foci consisting of the cluster of GGT-positive cells were not observed in these groups. The number of GGT-positive cells was not significantly increased in the DEN +
DC groups compared with that in the DEN alone group (Fig. 3a). However, the PCNA-positive cell ratio was significantly increased in the $750 \mathrm{ppm}$ DC group compared with that in the DEN alone group (Fig. 3b).

\section{mRNA expression in liver tissues}

The results of the analyses are summarized in Fig. 4. A significant up-regulation of stress response-related genes such as Cypla1 and Cypla2 was observed in mice administered $375 \mathrm{ppm}$ DC or more and mice in the DC-treated groups as compared with the control group, respectively. The expression of $O G G 1$, a DNA related gene, was significantly up-regulated only in the $750 \mathrm{ppm}$ DC group compared with the control group. No significant differences were found in the expression of Heme oxygenase 1 (Hmox1, MN_010442), Ercc5, Por (NADPH), Txnrd1, Sod1, Gpx2, and oxidative stress-related genes between the DEN alone and DEN + DC groups.

Table 2. Body and liver weights of mice given DC after DEN initiation

\begin{tabular}{|c|c|c|c|c|c|c|c|}
\hline Group & \multicolumn{2}{|c|}{ DEN alone } & \multicolumn{2}{|c|}{$\mathrm{DEN}+\mathrm{DC} 187.5 \mathrm{ppm}$} & \multicolumn{2}{|c|}{$\mathrm{DEN}+\mathrm{DC} 375 \mathrm{ppm}$} & \multirow{2}{*}{$\frac{\mathrm{DEN}+\mathrm{DC} 750 \mathrm{ppm}}{10}$} \\
\hline Animal No. & & 7 & & 12 & & 12 & \\
\hline Body weight (g) & 43.8 & $\pm 6.5^{\text {a) }}$ & 43.5 & \pm 4.0 & 42.2 & \pm 4.0 & $41.4 \pm 3.2$ \\
\hline Absolute liver weight ( $\mathrm{g}$ ) & 2.0 & \pm 0.2 & 2.2 & \pm 0.9 & 1.9 & \pm 0.2 & $2.0 \pm 0.4$ \\
\hline Relative liver weight (\%) & 4.7 & \pm 0.2 & 5.0 & \pm 1.7 & 4.7 & \pm 0.5 & $4.8 \pm 0.8$ \\
\hline
\end{tabular}

a): Mean \pm S.D.

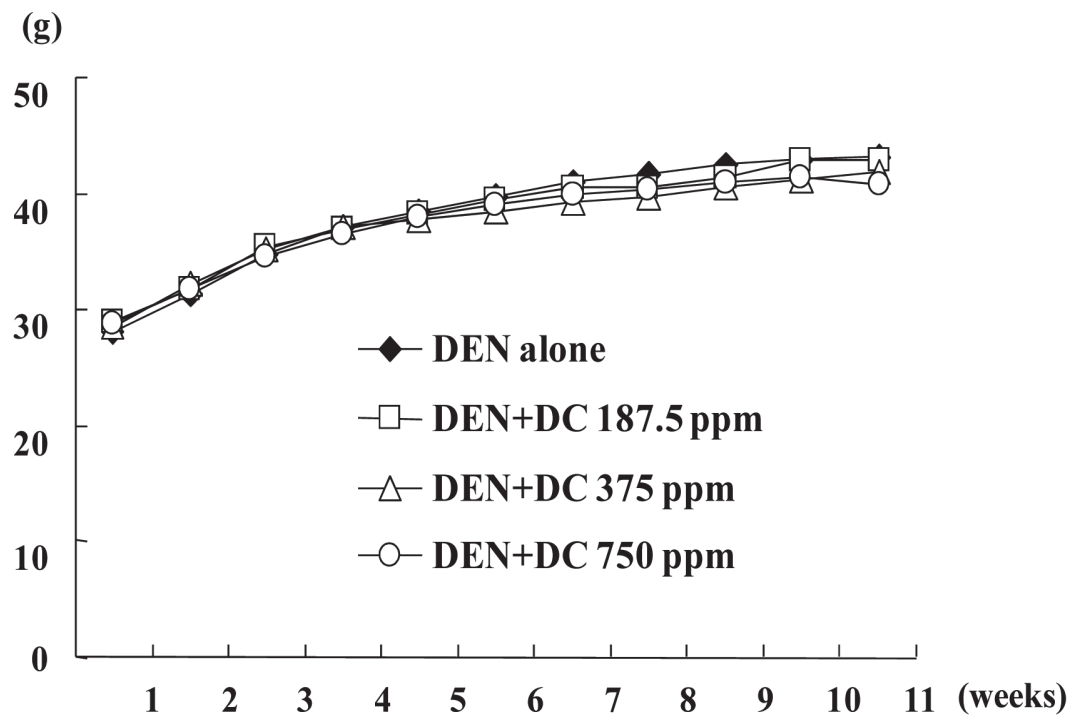

Fig. 2. Body weight changes of mice given DC for 10 weeks after DEN initiation 
M. Jin et al.
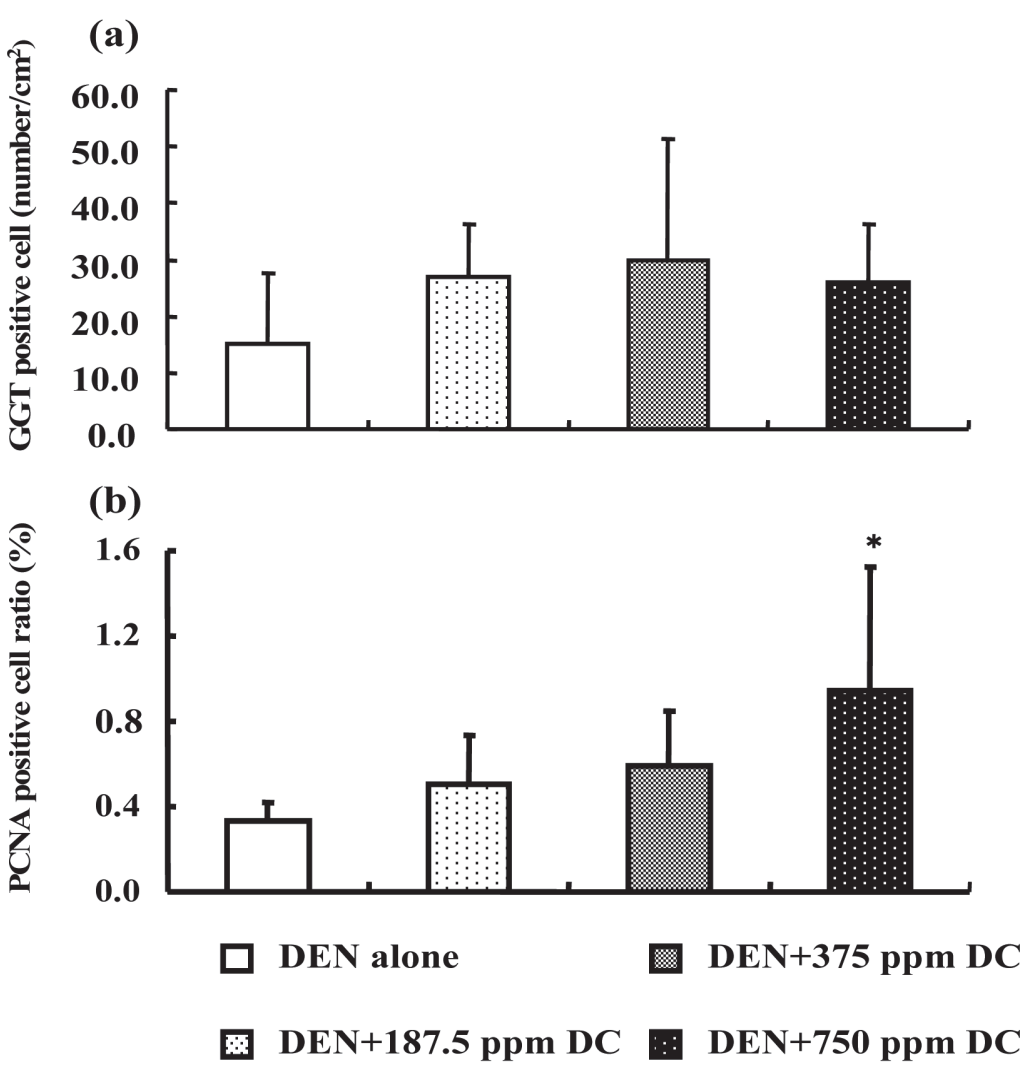

Fig. 3. The number of GGT positive cells and the PCNA positive ratio in mice given DC for 10 weeks after DEN initiation. Each graph shows the number of GGT-positive cells (a) and the PCNA-positive cell ratio (b) in the livers of mice given DC for 10 weeks after DEN initiation. Column represents means \pm S.D. *Significantly different from the 0 ppm DC group at $\mathrm{p}<0.05$ (Dunnett's test).

\section{Formation of microsomal ROS in liver}

As shown in Fig. 5, there was a tendency for increased formation of microsomal ROS in the liver of the DCtreated groups, but there were no significant differences between the DEN alone and DEN + DC groups.

\section{DISCUSSION}

DC has been reported to potentially exert hepatocarcinogenic and hepatocellular tumor-promoting effects in mice (WHO, 2000; Moto et al., 2005, 2006a and 2006b). In our previous study, we performed a two-stage liver carcinogenesis experiment in which partially hepatectomized mice were given 1,500 ppm DC for 8,13 or 20 weeks after initiation of hepatocarcinogenesis by DMN or DEN, and the number and area of GGT-positive foci and PCNApositive ratio were significantly increased in mice of the $\mathrm{DMN}+\mathrm{DC}$ or DEN + DC group compared with those in the DMN or DEN alone group (Moto et al., 2005, 2006a and 2006b). GGT is used as a marker for preneoplastic lesions in chemically induced hepatocarcinogenesis of mice (Peraino et al., 1983). In the present study, there was no increase in the number of GGT-positive cells in the livers of mice administered DC compared with that in the DEN alone group. However, immunohistochemical findings revealed a significant increase in the PCNA-positive ratio in the $750 \mathrm{ppm}$ DC group compared with that in the DEN alone group. It is has been reported that the amount of PCNA positive cells were corresponding with proliferative condition of the hepatic proliferative lesions (Chen et al., 1998). Furthermore, there are many reports that PCNA positive cell significantly increased in the liver of mice with the increased number of GGT positive foci or cells (Moto et al., 2005, 2006a and 2006b; Kenmochi et al., 2007). These results suggested the possibility that the present concentration of DC is not enough to the forma- 
Threshold of tumor promotion in DC
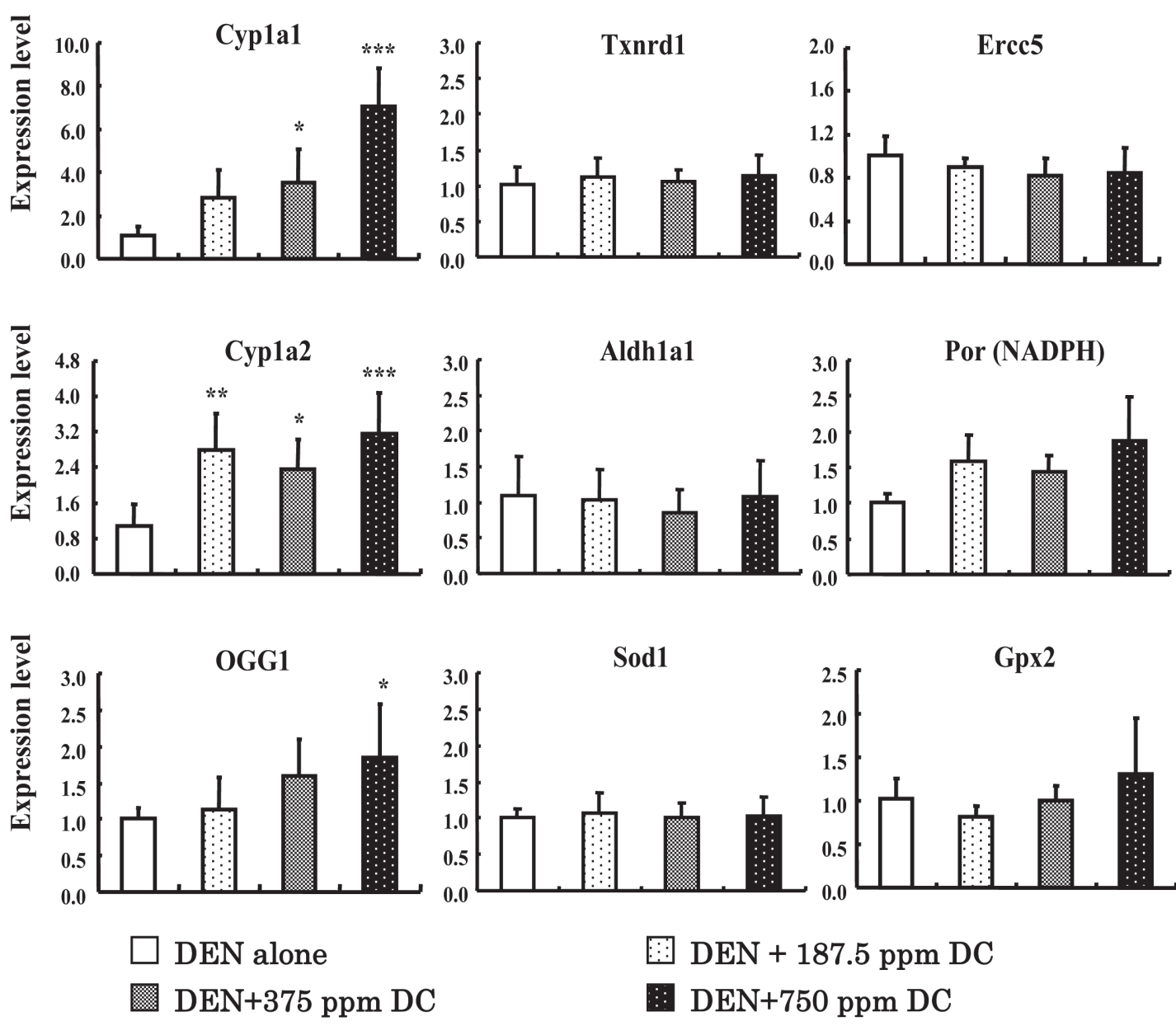

Fig. 4. Real time RT-PCR analysis of mRNA expression in the livers of mice given DC for 10 weeks after DEN initiation. The expression of target genes was normalized by $\beta$-actin. Values are expressed as the group mean fold change over control. Columns represents means \pm S.D. $* * *$ and $* * *$ significantly different from the $0 \mathrm{ppm}$ DC group at $\mathrm{p}<0.05, \mathrm{p}<0.01$ or $\mathrm{p}<0.001$, respectively (Dunnett's test).

tion of preneoplastic lesions, although an increase in cell proliferation activity was observed in the liver of mice given 750 ppm DC. Accordingly, the practical threshold level of DC that induces hepatocellular tumor-promoting effects was considered to be more than $750 \mathrm{ppm}$ in the present experimental condition.

The cytochrome P-450 family is known to generate ROS as byproducts of microsomal oxidation. Among the CYPs, CYP1A1 has been reported to be the most active CYP enzyme that catalyzes procarcinogens (Guengerrich and Shimada, 1991; Puntarulo and Cederbaum, 1998), and the up-regulation of the CYP1A1 and/or CYP1A2 isoform(s) indirectly results in the production of very large amounts of ROS compared with that of other CYPs (Paolini et al., 1996; Putarulo and Cederbaum,
1998; Valgimigli et al., 2001). In our previous studies in which mice were given diet containing 1,500 ppm DC after DMN/DEN initiation, a dose-dependent increase in microsomal ROS production was observed in these treated mice (Moto et al., 2005, 2006b). In the present study, the expressions of Cyplal in mice given 375 ppm DC or more and Cypla2 in mice from all of the DC-treated groups were significantly and higher than that in the DEN alone group, although there were no significant differences in the formation of microsomal ROS between the DEN alone and DEN + DC groups. These findings may suggest a possible generation of ROS through $\mathrm{P} 450$-mediated metabolism of DC and that the ROS produced in the liver of mice given DC is derived from the microsomes. On the other hand, it is also well known that ROS gen- 


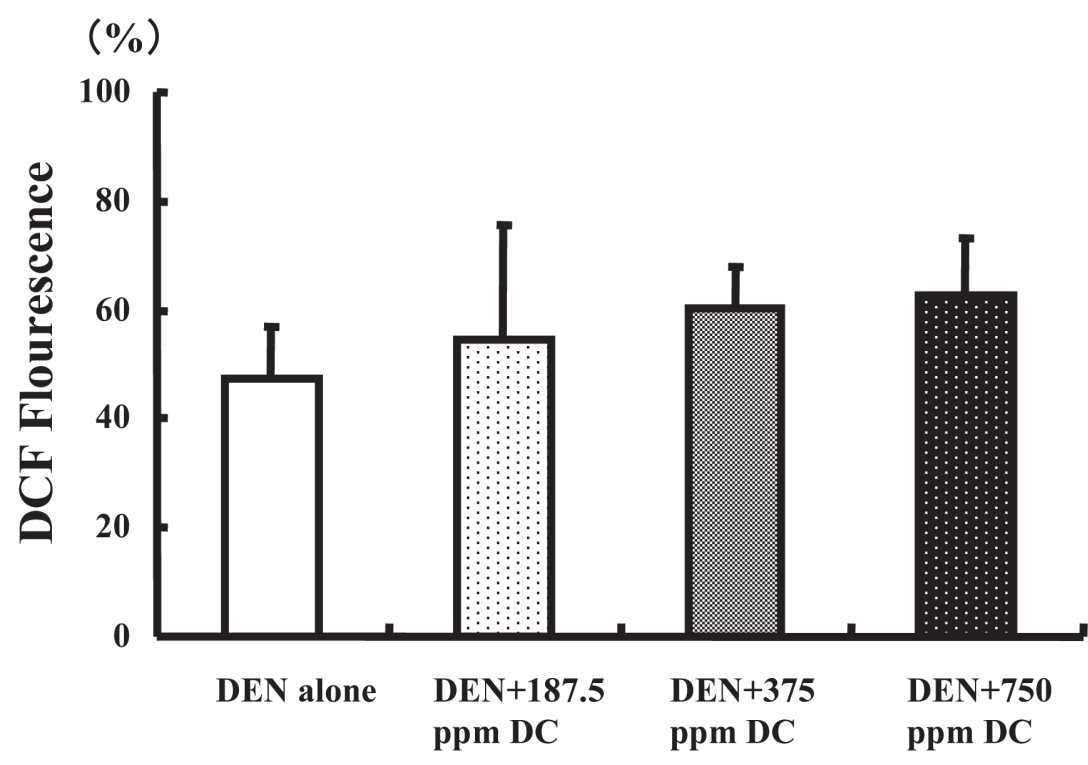

Fig. 5. Effect of DC on hepatic microsomal ROS production. Column represents mean \pm S.D.

erates from other cellular organelle in hepatocytes, such as mitochondria and peroxisomes (Parola and Robino, 2001), and macrophages (Kupffer cells) (Loguercio and Federico, 2003). However, no morphological changes were observed in Kupffer cells as well as mitochondria and peroxisomes of hepatocytes in DC-treated mice in our previous and present studies (Moto, et al., 2005, 2006a and 2006b). Therefore, the possibility that ROS generated from these organelles and Kupffer cells in DCtreated mice can be eliminated.

In the preset study, the formation of microsomal ROS in the liver tended to increase in the DC-treated groups, but there were no significant differences between the DEN alone and DC-treated groups. This finding may suggest that no oxidative DNA damage occurs in mice given 750 ppm DC or lower. On the other hand, the expression of $O G G 1$ was significantly increased only in the 750 ppm DC group compared with that in the control group. $O G G 1$ is a repair gene of $8-\mathrm{OHdG}$ (Kinoshita et al., 2002, 2003). 8-OHdG, a marker of oxidative DNA damage, is known as one of the causes for DNA point mutations such as G-T transversion (Kasai, 1997; Shibutani et al., 1991), and is potentially involved in the carcinogenesis in various experimental models (Nakae et al., 1997; Yoshida et al., 1999; Kinoshita et al., 2002, 2003). The up-regulation of the $O G G 1$ gene in the present study indicates that oxidative DNA damage in mice given $750 \mathrm{ppm}$ DC may be prevented by this DNA repair gene. On the other hand, the mRNA expression of metabolism-, oxidative stress- or DNA damage-/repair-related genes, such as Txnrd1, Por, Aldh1a1, Sod1, Gpx2 and Ercc5, in the DCtreated groups was not significantly higher than that in the DEN alone group. These findings may indicate that neither oxidative stress nor DNA damage is induced in mice given DC at concentrations of $750 \mathrm{ppm}$ or lower. Taking into account our results, we speculate that Cyplal and Cypla2 are the most sensitive molecular markers of the treatment-related metabolic changes of DC, but the upregulation of these genes at a concentration of DC of 750 ppm or lower is not enough to produce ROS.

In conclusion, in the present study, an increased number of PCNA-positive cells, and enhanced expression of oxidative stress- or DNA damage-/repair-related genes such as Cypla1, Cypla2 and OGG1 were observed in the livers of mice given $750 \mathrm{ppm}$ DC compared with the DEN alone group, but the number of GGT-positive cells and formation of microsomal ROS were not increased in this group. Therefore, the results of our study suggest that the threshold dose for ROS-mediated liver tumor promotion of DC is more than $750 \mathrm{ppm}$. Accordingly, the possibility that hepatocellular proliferative lesions may be induced in mice given $750 \mathrm{ppm}$ DC or lower is extremely low. 
Threshold of tumor promotion in DC

\section{ACKNOWLEDGMENTS}

This study was partly supported by a grant in-aid for research on the safety of veterinary drug residues in food of animal origin from the Ministry of Health, Labor and Welfare of Japan (H19-shokuhin-ippan-011). We would like to thank Dr Mitsuyoshi Moto (FUJI Co., LTD.) for his helpful suggestions.

\section{REFERENCES}

Asare, G.A., Mossanda, K.S., Kew, M.C., Paterson, A.C., Kahler-Venter, C.P. and Siziba, K. (2006): Hepatocellular carcinoma caused by iron overload: a possible mechanism of direct hepatocarcinogenicity. Toxicology, 219, 41-52.

Chen, D., Yan, R. and Ye, Y. (1998): Influence of compensatory hepatocyte proliferation on the caricnogenesis of Nnitrosodimethylamine. Zhonghua. Bing. Li. Xue. Za. Zhi., 27, 105-108.

Della Porta, G., Dragani, T. A. and Manenti, G. (1987): Two-stage liver carcinogenesis in the mouse. Toxicol. Pathol., 15, 229-234.

Dewa, Y., Nishimura, J., Muguruma, M., Jin, M., Saegusa, Y., Okamura, T., Tasaki, M., Umemura, T. and Mitsumori, K. (2008): $\beta$-Naphthoflavone enhances oxidative stress responses and the induction of preneoplastic lesions in a diethylnitrosamine-initiated hepatocarcinogenesis model in partially hepatectomized rats. Toxicology, 244, 179-189.

Guengerich, F.P. and Shimada, T. (1991): Oxidation of toxic and carcinogenic chemicals by human cytochrome P-450 enzymes. Chem. Res. Toxicol., 4, 391-407.

Kasai, H. (1997): Analysis of a form of oxidative DNA damage, 8hydroxy-2'-deoxyguanosine, as a marker of cellular oxidative stress during carcinogenesis. Mutat. Res., 387, 147-163.

Kawai, M., Saegusa, Y., Dewa, Y., Nishimura, J., Kemmochi, S., Harada, T., Ishii, Y., Umemura, T., Shibutani, M. and Mitsumori, K. (2009): Elevation of cell proliferation via generation of reactive oxygen species by piperonyl butoxide contributes to its liver tumor promoting effects in mice. Arch. Toxicol. (in press).

Kenmochi, Y., Takahashi, M., Moto, M., Muguruma, M., Nishimura, J., Jin, M., Kohno, T., Yokouchi, Y. and Mitsumori, K. (2007): Reactive oxygen species are possibly involved in the mechanism of flumequine-induced hepatocarcinogenesis in mice. J. Toxicol. Pathol., 20, 55-64.

Kinoshita, A., Wanibuchi, H., Imaoka, S., Ogawa, M., Matsuda, C., Morimura, K., Funae, Y. and Fukushima, S. (2002): Formation of 8-hydroxydeoxyguanosine and cell-cycle arrest in the rat liver via generation of oxidative stress by Phenobarbital: association with expression profiles of p21(WAF/Cip1), cyclin D1 and Ogg1. Carcinogenesis, 23, 341-349.

Kinoshita, A., Wanibuchi, H., Morimura, K., Wei, M., Shen, J., Imaoka, S., Funae, Y. and Fukushima, S. (2003): Phenobarbital at low dose exerts hormesis in rat hepatocarcinogenesis by reducing oxidative DNA damage, altering cell proliferation, apoptosis and gene expression. Carcinogenesis, 24, 1389-1399.

LeBel, C.P., Ali, S.F., McKee, M. and Bondy, S.C. (1990): Organometal-induced increases in oxygen reactive species: the potential of 2',7'-dichloro fluorescin diacetate as an index of neurotoxic damage. Toxicol. Appl. Pharmacol., 104, 17-24.

Lee, G.H., Nomura, K. and Kitagawa, T. (1989): Comparative study of diethylnitrosamine-initiated two-stage hepatocarcinogenesis in $\mathrm{C} 3 \mathrm{H}, \mathrm{C} 57 \mathrm{BL}$ and BALB mice promoted by various hepatopromoters. Carcinogenesis, 10, 2227-2230.

Lin, P.H., Lin, C.H., Huang, C.C. Chuang, M.C. and Lin, P. (2007): 2,3,7,8-Tetrachlorodibenzo-p-dioxin (TCDD) induces oxidative stress, DNA strand breaks, and poly (ADP-ribose) polymerase1 activation in human breast carcinoma cell lines. Toxicol. Lett., 172, 146-158.

Loguercio, C., and Federico, A. (2003): Oxidative stress in viral and alcoholic hepatitis. Free. Radic. Biol. Med., 34, 1-10.

Moriya, K., Nakagawa, K., Santa, T., Shintani, Y., Fujie, H., Miyoshi, H., Tsutsumi, T., Miyazawa, T., Ishibashi, K., Horie, T., Imai, K., Todoroki, T., Kimura, S. and Koike, K. (2001): Oxidative stress in the absence of inflammation in a mouse model for hepatitis $\mathrm{C}$ virus-associated hepatocarcinogenesis. Cancer Res., 61, 43654370.

Moto, M., Okamura, M., Muguruma, M., Ito, T., Jin, M., Kashida, Y. and Mitsumori, K. (2006a): Gene expression analysis on the dicyclanil induced hepatocellular tumors in mice. Toxicol. Pathol., 34, 744-751.

Moto, M., Okamura, M., Muto, T., Kashida, Y., Machida, N. and Mitsumori, K. (2005): Molecular pathological analysis on the mechanism of liver carcinogenesis in dicyclanil-treated mice. Toxicology, 207, 419-436.

Moto, M., Umemura, T., Okamura, M., Muguruma, M., Ito, T., Jin, M., Kashida, Y. and Mitsumori, K. (2006b): Possible involvement of oxidative stress in dicyclanil-induced hepatocarcinogenesis in mice. Arch. Toxicol., 80, 694-702.

Nakae, D., Kobayashi, Y., Akai, H., Andoh, N., Sato, H., Ohashi, K., Tsutsumi, M. and Konishi, Y. (1997): Involvement of 8-hydroxyguanine formation in the initiation of rat liver carcinogenesis by low dose levels of N-nitrosodiethylamine. Cancer Res., 57, 1281-1287.

Paolini, M., Pozzetti, L., Pedulli, G.F., Cipollone, M., Mesirca, R. and Cantelli-Forti, G. (1996): Paramagnetic resonance in detecting carcinogenic risk from cytochrome P450 overexpression. J. Invest. Med., 44, 470-473.

Parola, M. and Robino, G. (2001): Oxidative stress-related molecules and liver fibrosis. J. Hepatol., 35, 297-306.

Peraino, C., Richards, W.L. and Stevens, F.J. (1983): Multistage hepatocarcinogenesis. Environ. Health Perspect., 50, 1-53.

Puntarulo, S. and Cederbaum, A.I. (1998): Production of reactive oxygen species by microsomes enriched in specific human cytochrome P450 enzymes. Free. Radic. Biol. Med., 24, 1324-1330.

Rutenburg, A.M., Kim, H., Fischbein, J.W., Hanker, J.S., Wasserkrug, H.L. and Seligman, A.M. (1969): Histochemical and ultrastructural demonstration of $\gamma$-glutamyl transpeptidase activity. J. Histochem. Cytochem., 17, 517-526.

Schlezinger, J.J., White, R.D. and Stegeman, J.J. (1999) Oxidative inactivation of cytochrome P-450 1A (CYP1A) stimulated by 3,3',4,4'-tetrachlorobiphenyl: production of reactive oxygen by vertebrate CYP1As. Mol. Pharmacol., 56, 588-597.

Serron, S.C., Dwivedi, N. and Backes, W.L. (2000): Ethylbenzene induces microsomal oxygen free radical generation: antibodydirected characterization of the responsible cytochrome P450 enzymes. Toxicol. Appl. Pharmacol., 164, 305-311.

Shibutani, S., Takeshita, M. and Grollman, A.P. (1991). Insertion of specific bases during DNA synthesis past the oxidation-damaged base 8-oxodG. Nature, 349, 431-434.

Szejda, P., Parce, J.W., Seeds, M.S. and Bass, D.A. (1984) Flow cytometric quantitation of oxidative product formation by polymorphonuclear leukocytes during phagocytosis. J. Immunol., 
M. Jin et al.

133, 3303-3307.

Trush, M.A. and Kensler, T.W. (1991): An overview of the relationship between oxidative stress and chemical carcinogenesis. Free Radic. Biol. Med., 10, 201-209.

Valgimigli, L., Pedulli, G.F. and Paolini, M. (2001): Measurement of oxidative stress by Epr radical-probe technique. Free Radic. Biol. Med., 31, 708-716.

WHO (2000): Toxicological evaluation of certain veterinary drug residues in food, fifty-fourth meeting of the joint FAO/WHO expert committee on food additives. WHO Food Additive Series
45, pp.75-89, International Programme on Chemical Safety World Health Organization, Geneva.

Wiseman, H. and Halliwell, B. (1996): Damage to DNA by reactive oxygen and nitrogen species: role in inflammatory disease and progression to cancer. Biochem. J., 313, 17-29.

Yoshida, M., Miyajima, K., Shiraki, K., Ando, J., Kudoh, K., Nakae, D., Takahashi, M. and Maekawa, A. (1999): Hepatotoxicity and consequently increased cell proliferation are associated with flumequine hepatocarcinogenesis in mice. Cancer Lett., 141, 99107. 